\title{
Teacher's Questioning Skills in Elementary Science Classroom to Facilitate Student's Higher-Order Thinking Skills
}

\author{
Metta Liana ${ }^{1}$ and Tiar Sugiarti ${ }^{2}$ \\ \{mettaliana@umrah.ac.id ${ }^{1}$, tiarsugiarti23@gmail.com ${ }^{2}$ \} \\ Faculty of Teacher Training and Education, Universitas Maritim Raja Ali Haji, Indonesia ${ }^{1}$, \\ Kinderfield Highfield School, Indonesia ${ }^{2}$
}

\begin{abstract}
Teachers need to have good inquisitive techniques because they help to train students cognitively. Therefore, this study aims to examine teacher's questioning skills to facilitate students in thinking at higher levels. A total of 150 teachers from the elementary school that partakes in online training activities were selected as participants. The results showed that the teacher's questioning skills through the HOTS were in a suitable category, while the evaluating and creating aspects were in the lower level.
\end{abstract}

Keywords: Bloom's Taxonomy, 21st-century skills, cognitive

\section{Introduction}

In the 21st-century, the rapid growth of technology is one of the significant challenges in the world order because Information and Communication Technology provides instant and fast access facilities, as well as interpersonal communication that needs to be handled wisely. However, children need to face a lot of challenges during this period by filtering all the information received. ICT has touched the field of education because it is spread across all modern societies [1]. The preparation of students in terms of knowledge, skills, literacy attitudes, digital science, and technology is one of the teacher's efforts in training them cognitively. This is achieved by applying higher-order thinking skills including critical thinking, problem-solving, creativity, innovation, communication, and collaboration in learning [2].

In Indonesia, the learning process is in line with education policy on the National Assessment to foster reasoning power and student's character [3]. Therefore, teachers need to facilitate students to develop their thinking potential, find ideas, inspire imagination and promote action by asking questions. The questioning skills help to achieve goals and stimulate student's mental activity because their quality determines the effectiveness of learning in the classroom. Furthermore, teachers need to focus on the proper inquisitive techniques to foster students' interest in learning. These questioning skills tend to increase motivation and improve student's ability to think critically and creatively. Also, these inquisitive techniques help students to be actively involved in the teaching and learning process, as well as stimulate the mastery of higher-order thinking skills. These questioning skills help teachers in explaining the importance of a concept to allow students to understand and develop their thinking to a higher level [4].

The questions normally asked while teaching and learning varied with the level of asking that is divided into two parts including lower and higher-order thinking skills [5]. 


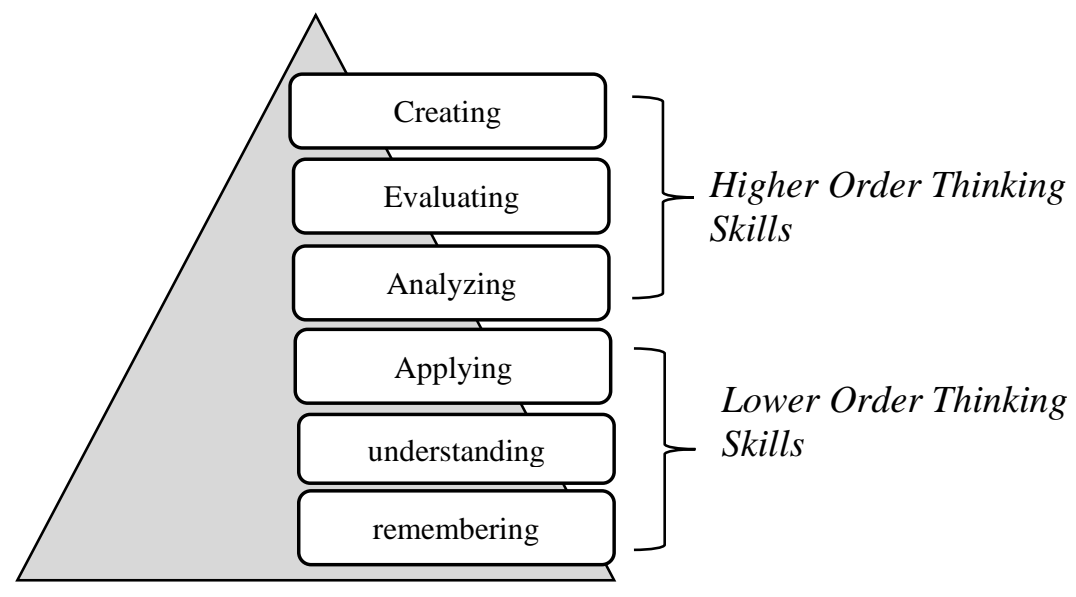

Fig 1. Revised Bloom's Taxonomy

The lower-order thinking skills in the teaching and learning process are remembering, understanding, and applying, while the higher-order thinking includes analyzing, evaluating, and creating. However, teachers need to promote students by asking questions at a higher level because they are expected to engage in more creative and stimulating thought processes [6]. In 21 st-century, higher-order thinking skills including cognitive domains, critical and creative thinking, as well as problem-solving are needed in learning. Meanwhile, teachers still focus on low-level questions or primary memory that [7], [8] only need short answers [9] for various reasons [10]. This negatively affects the students because they are not used to the critical thinking needed to succeed in life. Therefore, teachers need to change their learning process by planning questions that tend to help them remember information and require students to analyze, evaluate, as well as create.

Questions become one of the most powerful teaching tools because it affects student's thinking processes, hence teacher should improve their questioning skills [11], [12]. Also, students need to be motivated by asking higher-level questions if they are expected to engage in more creative and stimulating thought processes. This study aims to describe the skills of elementary school teachers in asking questions related to science material in online training activities with the title "Developing Higher-Order Thinking Skills Through Learning with an Inquiry Approach."

\section{Methodology}

\subsection{Research Method}

This study is qualitative descriptive in nature and aims to describe the skills of elementary school teachers in asking questions related to science material in online training activities titled "Developing higher-order thinking skills through learning with an inquiry approach." A total of 150 teachers from the elementary school spread across various parts of Indonesia were selected as participants. 


\subsection{Research Instrument}

An online written test with description answers from the teachers was performed using the padlet.com application. This instrument contains three questions including analyzing, evaluating, and creating aspects. However, the training instructor provides an Inquiry, HOTS, Science Process Skills, Virtual Practicum materials on temperature and heat, as well as examples of questions to train the teachers before giving the test. The learning activity scenario continued by presenting a heat transfer problem in daily life. Subsequently, the teachers are asked to make guiding questions that develop students' higher-order thinking skills.

\subsection{Analysis Data}

Data were obtained in a list of answers that raise higher-order thinking skills. The following is an equation to determine the percentage of variation due to the HOTS.

where:

$$
P=\frac{f}{N} \times 100 \%
$$

$P=$ Percentage of correct question variations by HOTS

$f=$ Variations of correct questions based on HOTS

$N=$ Number of variations of questions that appear

Table 1 shows the category of the teacher asking skills in raising HOTS questions

Table 1. Criteria for the teacher's questioning skill category to raise HOTS questions

\begin{tabular}{cc}
\hline Percentage & Questioning skill criteria \\
\hline $0 \%<x \leq 25 \%$ & Very low \\
$25 \%<x \leq 50 \%$ & Low \\
$50 \%<x \leq 75 \%$ & Very \\
$75 \%<x \leq 100 \%$ & Very well \\
\hline
\end{tabular}

\section{Result and Discussion}

The following activities are important after presenting materials related to the development of higher-order thinking skills in various virtual practicums. Firstly, the teachers try out inquiry learning activities that present a new problem independently. Second, the teachers made a list of questions regarding the problems displayed on the padlet.com application. The following shows the sequence of activities performed by the teacher.

Activity: Heat transfer on seeds 
Problem: Every morning, you use a spoon to stir the sugar which dissolves quickly while making a hot tea. There are spoons made of various materials to keep the tea warm.

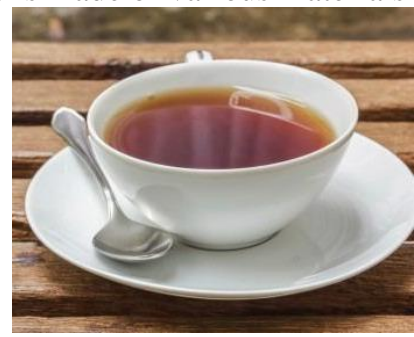

Fig 2. A cup of hot tea

Description of the virtual experiment: In this virtual experiment, there is an electric heater, butter, and seeds, as well as five spoons with different materials including aluminum, iron, glass, plastic, and wood. Meanwhile, smeared butter and seed are placed at one end of each spoon and the other end is dipped into water that has been heated using an electric heater. Teachers were allowed to observe the events and asked to design guiding questions that elicit higher-order thinking skills.

However, the questions made by the teacher are grouped based on the indicators of HOTS including analyzing, evaluating, and creating. Figure 3 shows the question quality categories that are obtained for each indicator.

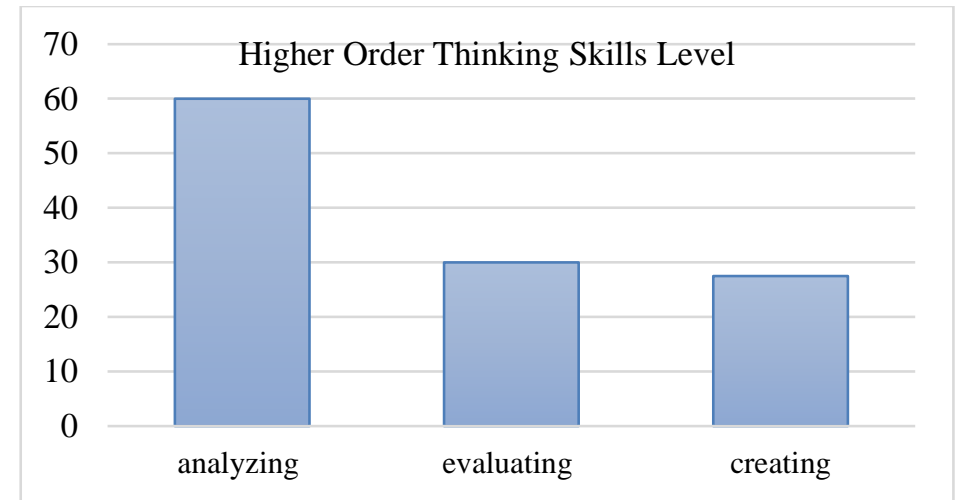

Fig 3. Category Teacher Questioning Skills in Practicing Higher Order Thinking Skills

Figure 3 shows that $60 \%$ of the variety of questions written by the teacher are good analytical skills. Furthermore, the teacher's questions for the indicators of evaluating and creating are in the lower category with a percentage of $30 \%$ and $27.5 \%$ respectively. The following tables show the explanation of each indicator.

Table 2 shows the numbers $1,3,4,6,8,9,11,13$, and 14 to be the designed questions that explain teacher's inquisitive techniques to analyze. Therefore, the teacher asked students questions to solve the material and group it into interconnected parts due to the aiming objectives. This question contains elements of comparing, looking for causes, and giving reasons, as well as stimulating students' thinking to reason and argue sustainably [13]. 
Table 2. Results of Teacher Question Variations for HOTS on Analyzing Levels

\begin{tabular}{clc}
\hline No. & \multicolumn{1}{c}{ Variations of Teacher Question } & Question Category \\
\hline 1 & Why do the seeds on the end of the spoon fall at different times? & True \\
2 & What material spoon falls first? What is the reason? & False \\
3 & Which seed on the spoon falls first? & True \\
4 & Which ingredient melts butter the fastest? & True \\
5 & Which is the fastest spoon that melts? & False \\
6 & Which seed fell first and last in this experiment? & True \\
7 & What is the difference in the speed of the fall? & False \\
8 & Why does butter melt at different times? & True \\
9 & Compare the spoon material based on the speed of seeds fall. & True \\
10 & What is the purpose of putting butter on each spoon? & False \\
11 & What causes the difference in seeds drops? Which seeds fall early and & True \\
& last? What factors influence? & \\
12 & What do you think caused the butter to melt? & False \\
13 & What causes each of the seeds to drop at different times? & True \\
14 & Compare the spoon material that make the butter melt first & True \\
15 & Which is the fastest material that drops the seeds and butter? & False \\
\hline
\end{tabular}

Table 3. Results of Teacher Question Variations for HOTS on Evaluations Levels

\begin{tabular}{|c|c|c|}
\hline No. & Variation of teacher's questions & Question Category \\
\hline 1 & $\begin{array}{l}\text { Determine with a spoon what material tend to make the water stay } \\
\text { warm for a long time. }\end{array}$ & False \\
\hline 2 & Why do aluminum spoons conduct heat faster than wooden ones? & False \\
\hline 3 & $\begin{array}{l}\text { Based on the experimental results, which spoon has the } \\
\text { characteristics of a conductor and an insulator? Explain your } \\
\text { answer! }\end{array}$ & False \\
\hline 4 & How could that happen? & False \\
\hline 5 & What is the effect of spoon material on the speed of falling seeds? & True \\
\hline 6 & Which seeds fall in the third tier? & False \\
\hline 7 & $\begin{array}{l}\text { How does the spoon-making material affect the rate at which the } \\
\text { seeds fall? }\end{array}$ & True \\
\hline 8 & $\begin{array}{l}\text { What about the speed at which seeds fall on an aluminum and a } \\
\text { wooden spoon? }\end{array}$ & False \\
\hline 9 & How do you experiment to get accurate information? & True \\
\hline 10 & $\begin{array}{l}\text { Make a conclusion from the practicum that you have done proven } \\
\text { by the experimental table! }\end{array}$ & False \\
\hline 11 & From analyzing, which the fastest spoon that melts the seeds? & False \\
\hline 12 & Make a sequence of spoons that melts the fastest using pictures! & True \\
\hline 13 & Try to compare the time difference shown by each spoon! & False \\
\hline 14 & $\begin{array}{l}\text { The fastest object that melts } \\
\text { The slowest object that melts }\end{array}$ & True \\
\hline 15 & $\begin{array}{l}\text { In a tabular form, make the results of the observations that have been } \\
\text { made to the experiment! }\end{array}$ & False \\
\hline 16 & Which seed in the spoon fell faster and why? & False \\
\hline 17 & What causes an aluminum spoon to quickly drop seeds? & False \\
\hline 18 & Organize data from butter-melting spoons! & False \\
\hline
\end{tabular}

Table 3 shows the numbers $5,7,9,12$, and 14 to be the questions that explain the teacher's inquisitive techniques to evaluate. However, the evaluation aspect is categorized as low-order 
thinking skills because only a few variations of questions provoke answers to make choices or judgments based on criteria or standards.

Table 4. Results of Teacher Question Variations for HOTS on Creating Levels

\begin{tabular}{clc}
\hline No. & \multicolumn{1}{c}{ Variations of Teacher Question } & Question Category \\
\hline 1 & Make a table to record the data from this experiment! & False \\
2 & Make a poster about which spoon melts fast! & True \\
3 & $\begin{array}{l}\text { What to do to make the seeds on the end of the aluminum and iron } \\
\text { spoon fall together? }\end{array}$ & False \\
4 & Make data if butter is replaced with other ingredients! & False \\
5 & What happens if all the spoon ingredients are the same & False \\
6 & Make a hypothesis about the experiment performed & False \\
7 & Write down the results of the experiments you have done! & False \\
8 & Arrange the materials from the fastest to the slowest to conduct heat! & False \\
9 & How can these materials be used to make a tool from a cooking pot? & True \\
& State the reason! & \\
10 & Make a good spoon ad for consuming soup! & True \\
\hline
\end{tabular}

Table 4 shows the numbers 2, 9, and 10 are the questions that explain the teacher's inquisitive techniques to create. However, indicates that teachers have the low level of creating category. Also, only few questions lead to the arrangement of elements or new structures.

The low teacher's questioning skills for evaluating and creating are caused by the inaccurate answers given. The following are the errors that occur: First, the number 2 and 5 questions given by the teacher are not clear; second, the number 2 and 3 questions need to be categorized as an analyzing aspect instead of evaluating and vice versa; third, the duration of thinking and the time spent to give a short answer; and fourth, the number 5 question leads to the lack of material understanding or the experiments performed. The question "What happens if all the spoon ingredients are the same?" tend not to give any change because teachers are not used to HOTS questions in class but actively ask students a low-level one [8].

However, a teacher that asked higher-order thinking questions has a good understanding of the subject matter. This type of teacher needs to involve in lessons to help students connect meaningful knowledge and integrate new subject matter into their cognitive structures [14]. Moreover, meaningful learning occurs when learners use existing knowledge to understand new experiences [15].

\section{Conclusion}

This study shows that the questioning skills that facilitate HOTS are still low in the evaluating and creating aspects, while the average teacher raises questions that are in the analysis category. In the future, teachers need to develop better inquisitive techniques through continuous training activities, increasing understanding of teaching content, and reading various kinds of literature related to learning models/approaches in the classroom. These skills facilitate students to gain experiences in developing conceptual understanding through the questions given, processing knowledge, and submitting opinions following their critical thinking patterns [16],[17]. Therefore, the art of asking some critical questions is to train students to think at a higher level. 


\section{Acknowledgments}

The author thanks the elementary science teachers that participated in this study.

\section{References}

[1] M. Liana and O. Alpindo, "Pengembangan e-Worksheets Berorientasi ICT Literacy Pada Mata Kuliah Pengantar Teknologi Informasi Pendidikan Matematika Untuk Mahasiswa Tahun Pertama," J. Cendekia J. Pendidik. Mat., vol. 5, no. 1, pp. 223-237, 2021.

[2] A. R. Saavedra and V. Darleen Opfer, "Learning 21st-century skills require 21stcentury teaching," Phi Delta Kappan, vol. 94, no. 2, pp. 8-13, 2012.

[3] Kemendikbudristek, "Regulation of the Minister of Education, Culture, Research, and Technology of the Republic of Indonesia number 17 the year 2021 on national assessment," pp. 1-10, 2021.

[4] G. Shanmugavelu, K. Ariffin, M. Vadivelu, Z. Mahayudin, and M. A. R K Sundaram, "Questioning Techniques and Teachers' Role in the Classroom," Shanlax Int. J. Educ., vol. 8, no. 4, pp. 45-49, 2020.

[5] D. R. Krathwohl, “A Revision Of Bloom's Taxonomy Of Educational Objectives,” Theory Pract., vol. 41, no. 4, p. 302, 2002.

[6] A. W. Oliveira, "Improving teacher questioning in science inquiry discussions through professional development," J. Res. Sci. Teach., vol. 47, no. 4, pp. 422-453, 2010.

[7] A. T. Wood and C. H. Anderson, "The Case Study Method: Critical Thinking Enhanced by Effective Teacher Questioning Skills," Annu. Int. Conf. World Assoc. Case Method Res. Appl., pp. 1-12, 2001.

[8] T. Saeed, S. Khan, A. Ahmed, R. Gul, S. Cassum, and Y. Parpio, "Development of students' critical thinking: The educators' ability to use questioning skills in the baccalaureate programs in nursing in Pakistan," J. Pak. Med. Assoc., vol. 62, no. 3, pp. 200-203, 2012.

[9] M. L. Blanton, S. Westbrook, and G. Carter, "Using Balsiger's zone theory to interpret teaching practices in mathematics and science classrooms," J. Math. Teach. Educ., vol. 8, no. 1, pp. 5-33, 2005.

[10] M. A. B. Delcourt and J. McKinnon, "Tools for Inquiry: Improving Questioning in the Classroom," Learn. Landscapes, vol. 4, no. 2, pp. 145-159, 2011.

[11] C. Chin, "Teacher questioning in science classrooms: Approaches that stimulate productive thinking," J. Res. Sci. Teach., vol. 44, no. 6, pp. 815-843, 2007.

[12] G. Curtis, "The Impact of Teacher Efficacy and Beliefs on Writing Instruction," Delta Kappa Gamma Bull., vol. 84, no. 1, p. 17, 2017.

[13] A. Kawalkar and J. Vijapurkar, "Scaffolding Science Talk: The role of teachers' questions in the inquiry classroom," Int. J. Sci. Educ., vol. 35, no. 12, pp. 2004-2027, 2013.

[14] D. Y. Yip, "Questioning skills for a conceptual change in science instruction," J. Biol. Educ., vol. 38, no. 2, pp. 76-83, 2004.

[15] B. S. Bloom, M. D. Engelhart, E. J. Furst, W. H. Hill, and D. R. Krathwohl, "Taxonomy of Educational Objective," Taxon. Educ. Object., pp. 62-197, 1956.

[16] M. Iwasyk, E. H. van Zee, J. Wild, A. Kurose, and D. Simpson, "Student and teacher questioning during conversations about science," J. Res. Sci. Teach., vol. 38, no. 2, pp. 
159-190, 2001.

[17] M. Nieswandt and K. Bellomo, "Written extended-response questions as classroom assessment tools for meaningful understanding of evolutionary theory," J. Res. Sci. Teach., vol. 46, no. 3, pp. 333-356, 2009. 